\title{
Effect of soil subgrade modulus on raft foundation behavior
}

\author{
Omer Mughieda ${ }^{1, *}$ Mohamed Sherif Mehana $^{2}$, and Kenan Hazirbaba ${ }^{3}$ \\ ${ }^{1}$ Dept. of Civil Engineering, Abu Dhabi University, Abu Dhabi, UAE \\ ${ }^{2}$ UNii Engineering Consultancy, 47378, Abu Dhabi, UAE \\ ${ }^{3}$ Dept. of Civil Infrastructure and Environ. Eng, Khalifa University, Abu Dhabi, UAE
}

\begin{abstract}
The present study is carried out to investigate the effect of soil subgrade modulus on bending moment, shear, and deformation characteristics of raft foundation. Subgrade models are an approximate representation for the actual load-displacement behavior of the supporting soil. One of the widely-used methods to model soil subgrade modulus is "Winkler" method where the interaction between soil and foundations is represented by a number of springs. The main flaw of this model is the lack of coupling between springs and representation of the non-linearity of load settlement behavior of soil. In this work an attempt is made to analyze "Winkler "method through a commercial software (SAFE V2014) in terms of the effect of soil subgrade modulus on the behavior of raft foundation.
\end{abstract}

\section{Introduction}

The type of foundation used for any structure depends on various parameters such as geometric properties of the structure, super-structure loads, foundation material properties, foundation thickness and supporting soil sub-grade modulus. "Raft" or "Mat" foundation is commonly used in Abu Dhabi, UAE, especially to support low-rise building and light structures. A raft foundation is suitable where large settlements or differential settlements are anticipated. In general, use of a raft foundation proves to be more economical compared to spread footings in case spread footings would cover more than one third of structure footprint area [1].

A clear understanding of the behavior of raft foundation in relation to the supporting subgrade is mandatory to ensure the economy and safety in design, hence the objective of this paper is to examine the effect of supporting soil subgrade modulus on raft design. More specifically, this study focuses on the changes in raft straining actions and deflections due to the change in the value of soil subgrade reaction " $K s$ ".

\footnotetext{
* Corresponding author: omer.mughieda@adu.ac.ae
} 


\section{Design of raft foundation}

The structural design of a raft foundation can be carried out by two common methods: the conventional rigid method and the non-rigid method (e.g. Winkler method). In addition, finite difference and finite element methods can be used. As non-rigid methods consider the effects of raft deformations on the distribution of bearing pressure, relationship between settlement and bearing pressure needs to be defined. This can be done using the coefficient of subgrade modulus $(K s=q / \Delta$, where: $q=$ bearing pressure and $\Delta=$ settlement $)$.

\section{Soil subgrade modulus}

In Winkler method, bed springs are used to represent the interaction between soil and raft. The stiffness of springs depends on the value of coefficient of subgrade modulus $(K s)$. The magnitude of $K s$ depends on several factors such as width, shape, position and depth of the foundation. There is no single $K s$ value even if the aforementioned factors are well-defined, because the $q-\Delta$ relationship is nonlinear [1].

Various methods, such as field testing as well as empirical relations, have been developed to estimate $K s$. In this study, Ks was determined from Standard Penetration Tests (SPT) performed in four different locations in Abu Dhabi, UAE.

Meyerhof (1956) proposed correlation between net bearing pressure and "SPT" N60. According to Meyerhof theory, for $25 \mathrm{~mm}$ of estimated settlement [2]:

$$
\begin{gathered}
q_{\text {net }}(\mathrm{KN} / \mathrm{m} 2)=N 60 / 0.08(\text { for } B<1.22 \mathrm{~m}) \\
q_{\text {net }}(\mathrm{KN} / \mathrm{m} 2)=N 60 / 0.125((B+0.3) / B) 2(\text { for } B>1.22 \mathrm{~m})
\end{gathered}
$$

Where:

$F d=$ depth factor $=1+0.33(D f / B)$

$B=$ Foundation depth in meter.

$S e=$ settlement in $\mathrm{mm}$.

Researchers [2-6] have observed that Meyerhof (1956) results are conservative. Later Meyerhof (1965) suggest that the net bearing pressure should be increased by $50 \%$. Bowles (1977) proposed that the modified form of bearing equations to be expressed as:

$$
\begin{gathered}
\text { qnet }(\mathrm{KN} / \mathrm{m} 2)=(N 60 / 2.5) * F d *(\mathrm{Se} / 25)(\text { for } B<1.22 \mathrm{~m}) \\
q \operatorname{qnet}(\mathrm{KN} / \mathrm{m} 2)=N 60 / 0.08((B+0.3) / B) 2 * F d *(\operatorname{Se} / 25)(\text { for } B>1.22 \mathrm{~m})
\end{gathered}
$$

Generally shallow foundations are designed for a maximum settlement of $25 \mathrm{~mm}$ and differential settlement of $19 \mathrm{~mm}$. However, the width of rafts is larger than isolated spread footings, hence the depth of zone of influence is much larger than that of spread footing. Hence the loose soil pockets under Raft may be more evenly distributed. Accordingly, maximum settlement can be assumed to be $50 \mathrm{~mm}$ and differential settlement to be $19 \mathrm{~mm}$ [2].

Using the above-mentioned assumptions and conservatively assuming $F d=1.0$, (Eq.4) can be assumed as following:

$$
\text { qnet }(\mathrm{KN} / \mathrm{m} 2)=25 * N 60
$$

Using actual N60 values obtained from "SPT" performed in five different locations in Abu Dhabi. Figure 1 shows the studied locations. Using Meyerhof (1965) theory modified by Bowles; soil subgrade modulus were calculated and tabulated in Table 1. 


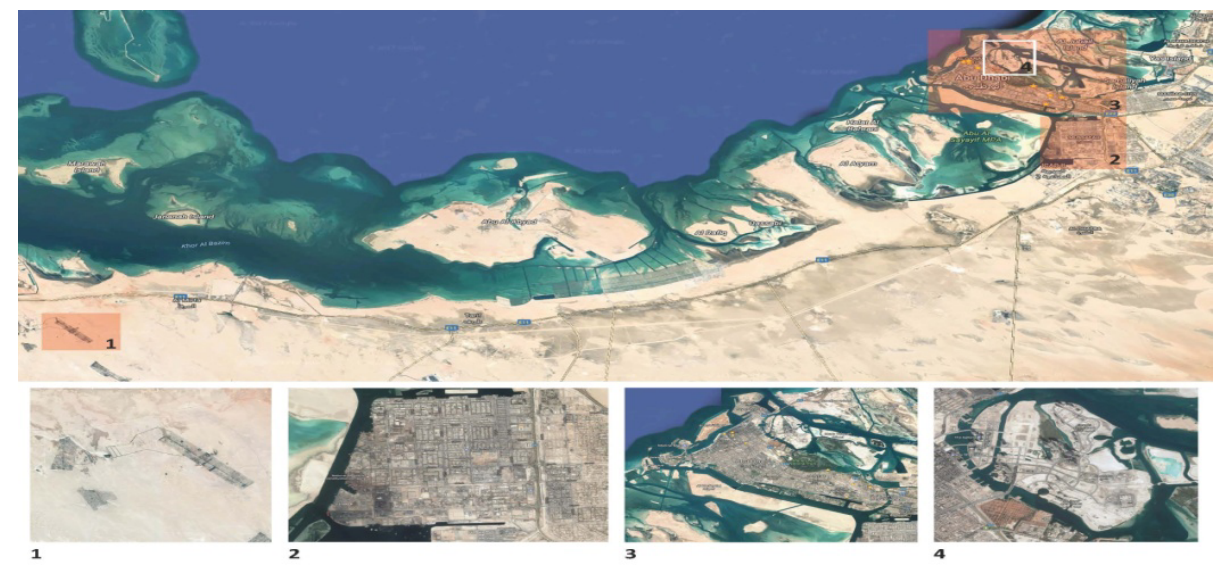

Fig. 1. Areas in Abu Dhabi considered in the study.

Table 1. Subgrade modulus values for different areas in Abu Dhabi.

\begin{tabular}{|c|c|c|}
\hline & Location & $\boldsymbol{K s}\left(\mathbf{k N} / \mathbf{m}^{\mathbf{3}}\right)$ \\
\hline 1 & Madinat Zayed-Werstern reigion & 25000 \\
\hline 2 & Mussafah city & 21500 \\
\hline 3 & Abu Dhabi island & 10000 \\
\hline 4 & Reem island & 15000 \\
\hline
\end{tabular}

\section{Analysis of raft foundation}

In this study, the effect of soil subgrade modulus on raft has been investigated using finite elements method. Shell element have been used to define raft foundation shown in Figure 2. Area springs used to represent soil subgrade modulus based on " $K s$ " values illustrate in Figure 1.

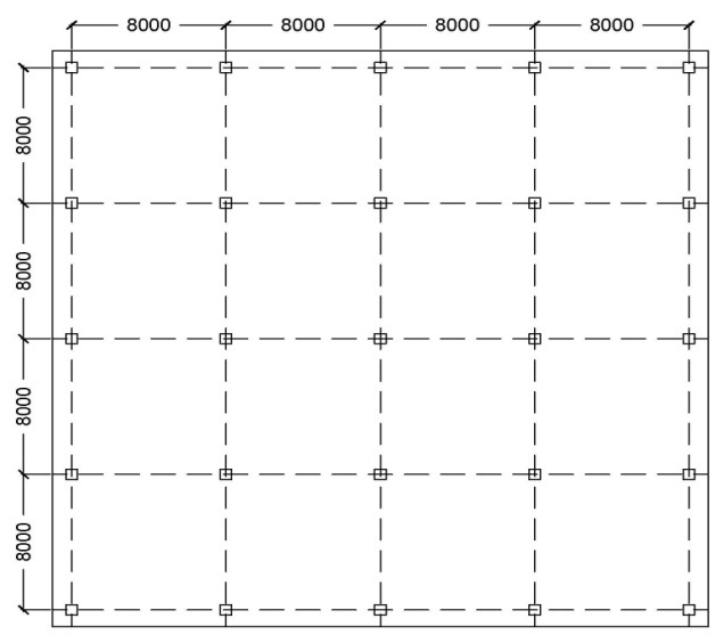

Fig. 2. Plan view of raft foundation for 10 story building 


\section{Effect of soil subgrade reaction on bending moment and shear forces}

Figures 3, 4 \& 5 represent bending moment for column strip, bending moment for middle strip and shear force diagram respectively corresponding to " $K s$ " equal to $1.0 \times 104$, $1.5 \times 104,2.15 \times 104 \& 2.5 \times 104 \mathrm{kN} / \mathrm{m}^{3}$. Bending moment and shear force are not very susceptible to the changes in values of soil " $K s$ ".

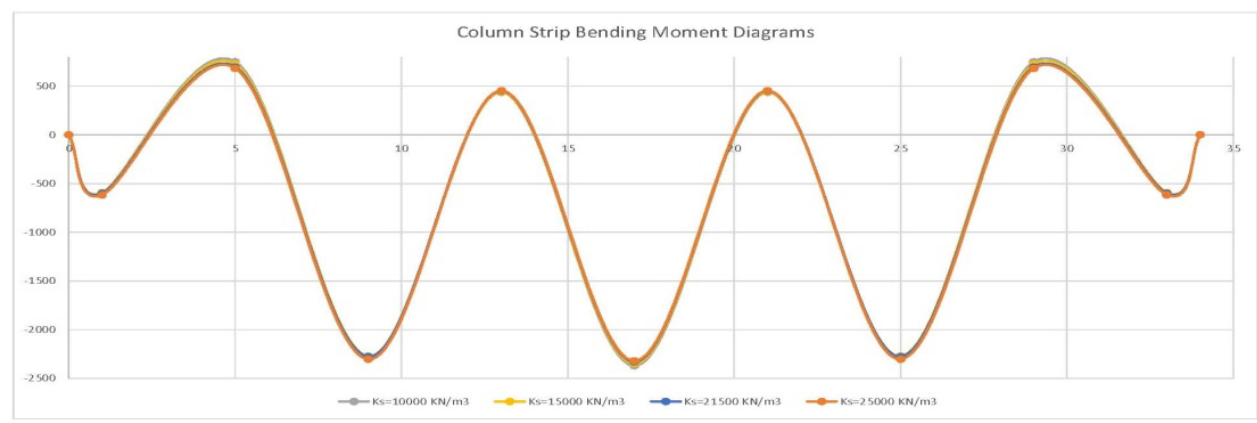

Fig. 3. Column strip bending moment diagram

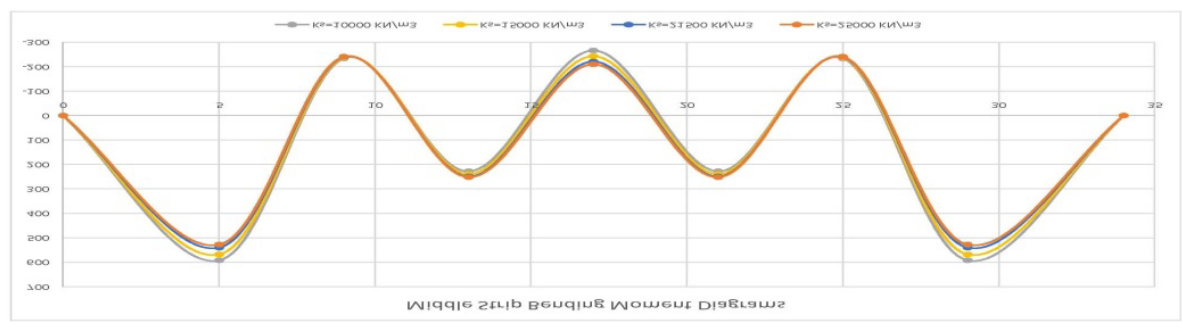

Fig. 4. Middle strip bending moment diagram

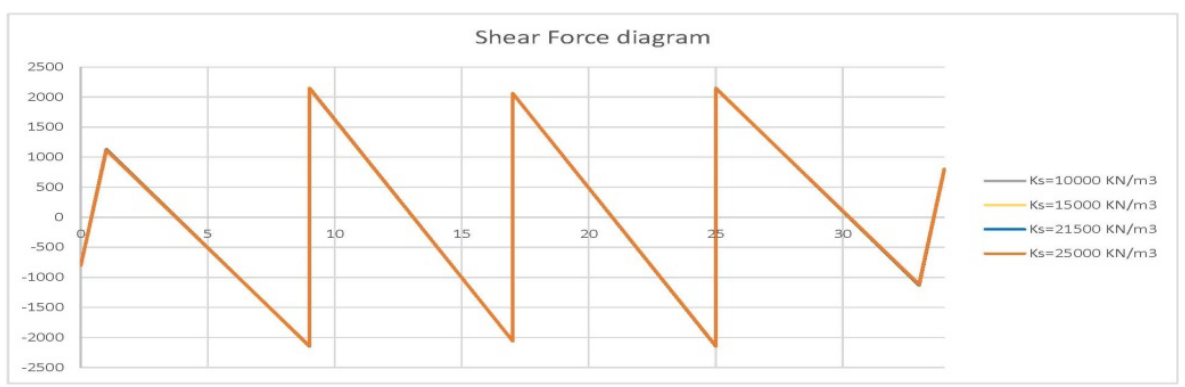

Fig. 5. Column strip Shear force diagram

\section{Effect of soil subgrade reaction on raft deformation}

Figures $6,7,8 \& 9$ represent Raft deformations corresponding to " $K s$ " equal to $1.0 \times 104$, $1.5 \times 104,2.15 \times 104 \& 2.5 \times 104 \mathrm{kN} / \mathrm{m}^{3}$. 
By definition; settlement of Raft is inversely proportional to soil subgrade modulus $(K s=q / \Delta)$. In Figures 6, 7, $8 \&$ \&; settlement contour lines obtained by "SAFE" analysis indicate that settlement values decrease when " $K s$ " increase conforming the theoretical definition.

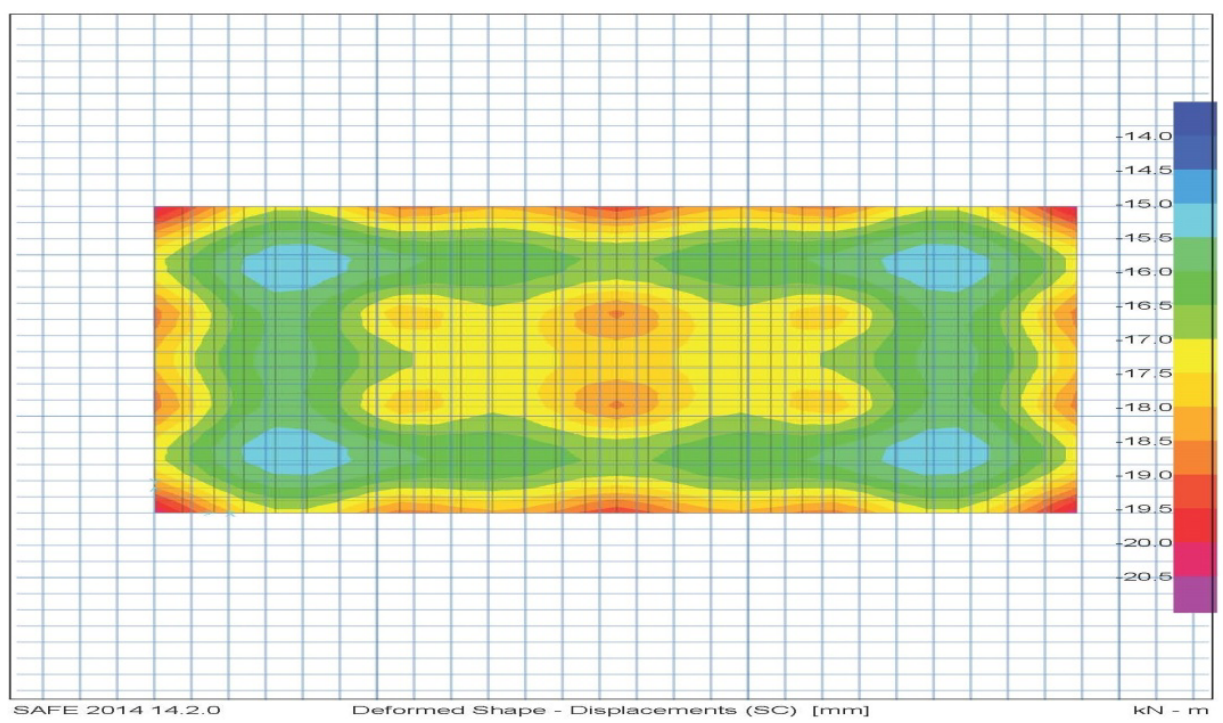

Fig. 6. Raft deformations $\left(K s=10000 \mathrm{kN} / \mathrm{m}^{3}\right)$.

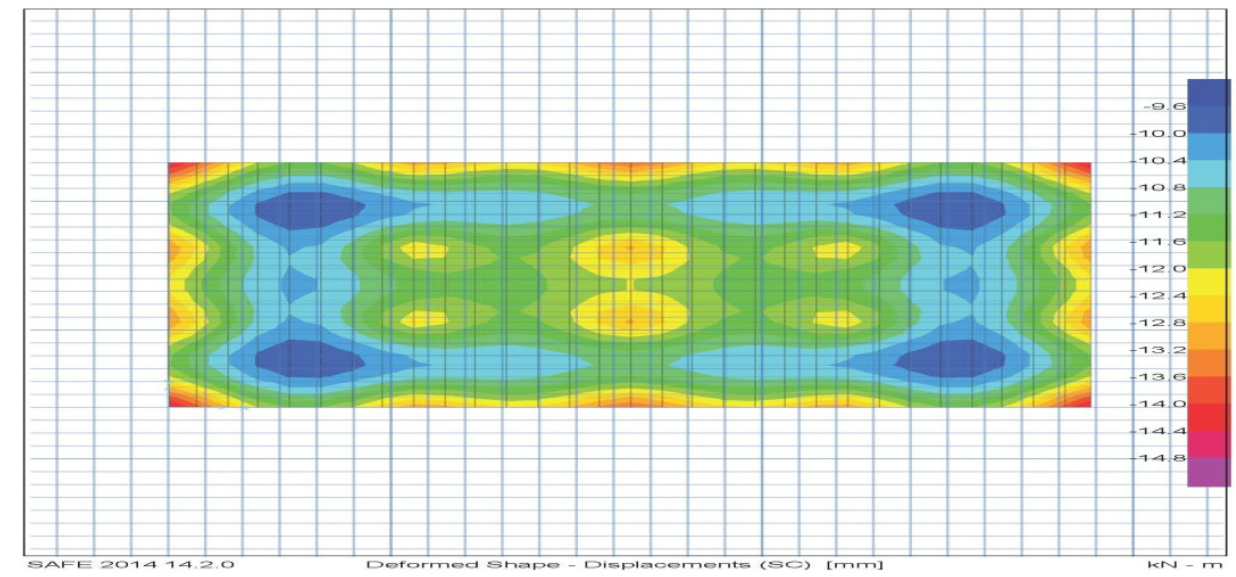

Fig. 7. Raft deformations $\left(K s=15000 \mathrm{kN} / \mathrm{m}^{3}\right)$. 


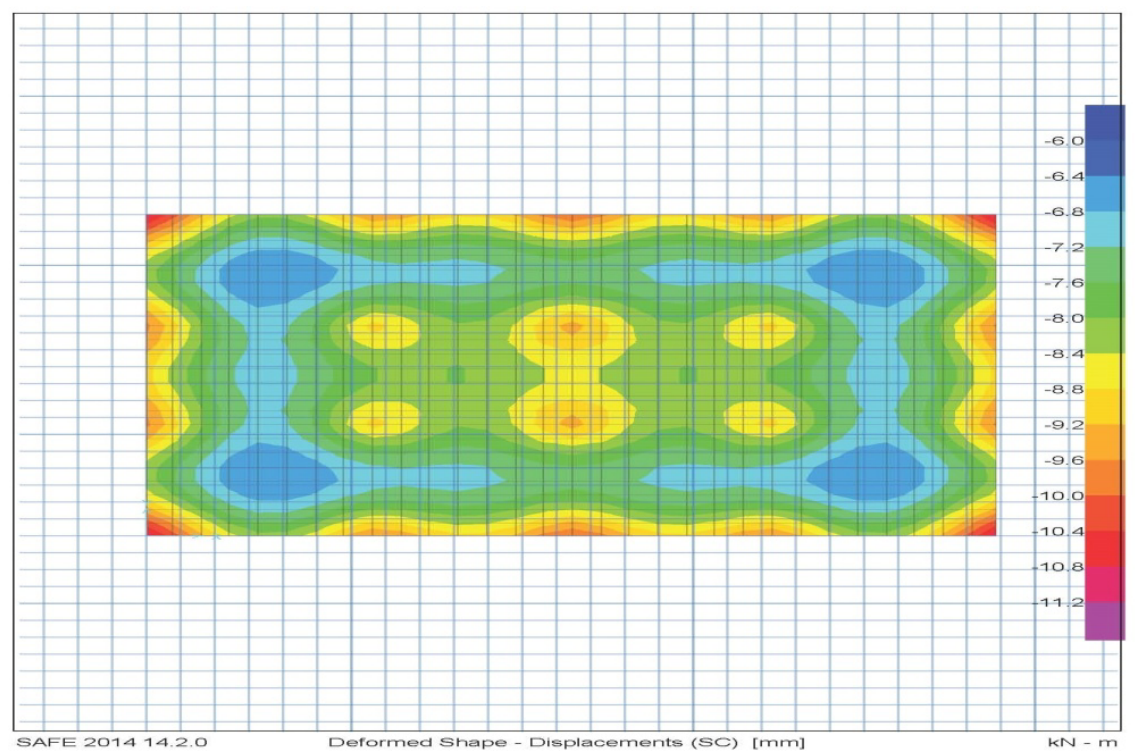

Fig. 8. Raft deformations $\left(K s=21500 \mathrm{kN} / \mathrm{m}^{3}\right)$.

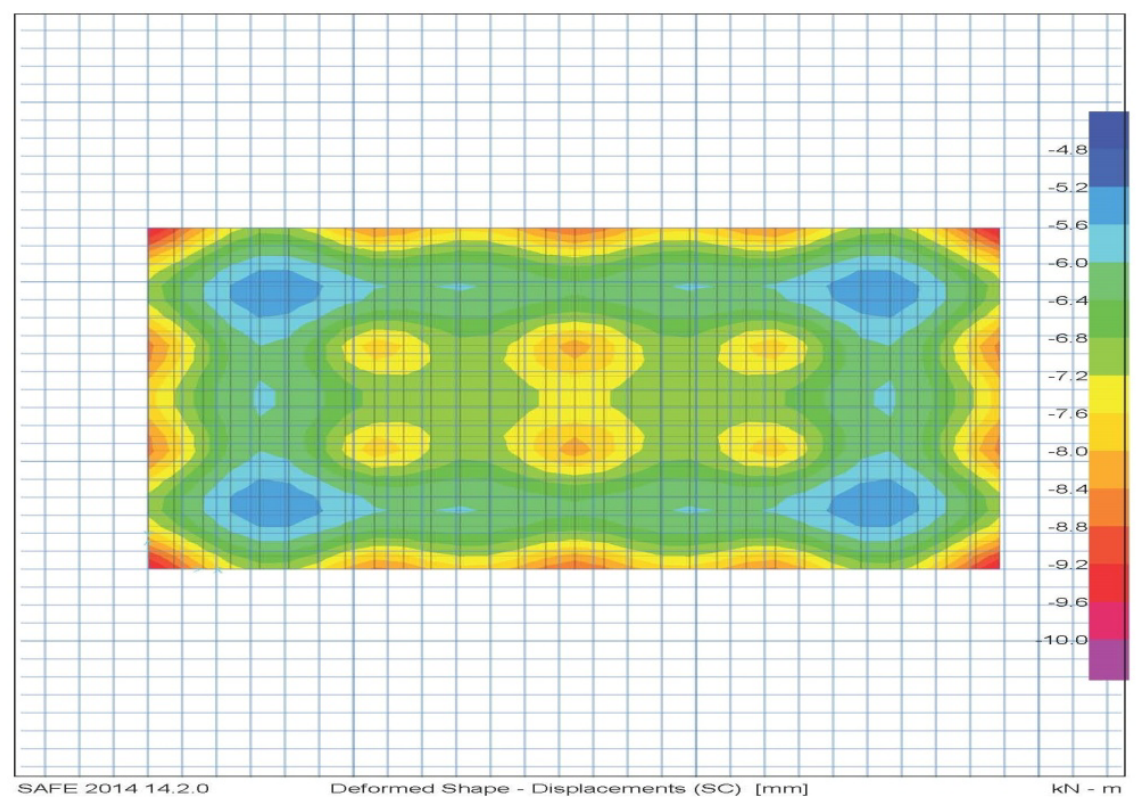

Fig. 9. Raft deformations $\left(K s=25000 \mathrm{kN} / \mathrm{m}^{3}\right)$. 


\section{Conclusions}

In the present work, parametric study is carried out on the effect of soil subgrade modulus on behavior of Raft foundation. In the light of the preceding discussions the following conclusions can be drawn:

- Changes in the value of soil subgrade reaction have no significant impact on values of Raft straining actions. (Bending moment and shear force)

- Raft deflection decreases with increasing the value of soil subgrade reaction. However, it is recommended that these values should be verified using either empirical methods or field tests.

- Changing the value of soil subgrade modulus has significant effect on pressure distribution on soil below foundation. As soil subgrade modulus increases, bearing pressure is concentrated in springs below columns; while springs in between columns are less susceptible to pressure distribution. Hence, soil behavior tends to "rock" for high values of soil subgrade modulus.

\section{References}

1. D. P. Coduto, Foundation design, principles and practices, Prentice Hall, Englewood Cliffs, NJ, (1994).

2. B. Das, Principles of Foundation Engineering, seventh ed., Stamford, (2007).

3. J. E. Bowles, (1974), Analytical and Computer Method in Foundation Engineering, Mc Graw Hill Book Co., (1974)

4. J. E. Bowles, Foundation Analysis and Design, 5th Edition, Mc Graw Hill Book Co., New York, (1977).

5. S. C. Gupta, Raft Foundation Design and Analysis with A Practical Approach, New Age International. (2007).

6. A. S. Morshed, M. Monzurul, A Design Rationale for Mat Foundation Based on Finite Element Analysis. (1996). 